\title{
BMJ Open How is family health history discussed in routine primary healthcare? A qualitative study of archived family doctor consultations
}

\author{
Sara Filoche (D) , ${ }^{1}$ Maria H Stubbe, ${ }^{2}$ Rebecca Grainger (D) , ${ }^{3}$ Bridget Robson, ${ }^{4}$ \\ Karyn Paringatai, ${ }^{5}$ Phil Wilcox, ${ }^{6}$ Regina Jefferies, ${ }^{1}$ Anthony Dowell ${ }^{2}$
}

To cite: Filoche S, Stubbe MH, Grainger $\mathrm{R}$, et al. How is family health history discussed in routine primary healthcare? A qualitative study of archived family doctor consultations. BMJ Open 2021;11:e049058. doi:10.1136/ bmjopen-2021-049058

- Prepublication history for this paper is available online. To view these files, please visit the journal online (http://dx.doi. org/10.1136/bmjopen-2021049058).

Received 19 January 2021 Accepted 28 July 2021

Check for updates

(C) Author(s) (or their employer(s)) 2021. Re-use permitted under CC BY-NC. No commercial re-use. See rights and permissions. Published by BMJ.

For numbered affiliations see end of article.

Correspondence to

Dr Sara Filoche;

sara.filoche@otago.ac.nz

\section{ABSTRACT}

Objectives Family health history underpins genetic medicine. Our study aimed to explore language and patterns of communication relating to family health history observed in interactions between general practitioners (GPs) and their patients within routine primary care consultations.

Design Secondary analysis of patient and GP routine consultation data $(n=252)$.

Participants Consultations that included 'family health history' were eligible for inclusion $(n=58)$.

Primary outcomes A qualitative inductive analysis of the interactions from consultation transcripts.

Results $46 / 58$ conversations about family health history were initiated by the GP. Most discussions around family history lasted for between approximately 1 to $2 \mathrm{~min}$. Patients were invited to share family health history through one of two ways: non-specific enquiry (eg, by asking the patient about 'anything that runs in the family ); or specific enquiry where they were asked if they had a 'strong family history' in relation to a particular condition, for example, breast cancer. Patients often responded to either approach with a simple no, but fuller negative responses also occurred regularly and typically included an account of some kind (eg, explaining family relationships/ dynamics which impeded or prevented the accessibility of information).

Conclusions Family health history is regarded as a genetic test and is embedded in the sociocultural norms of the patient from whom information is being sought. Our findings highlight that it is more complex than asking simply if 'anything' runs in the family. As the collection of family health history is expected to be more routine, it will be important to also consider it from sociocultural perspectives in order to help mitigate any inequities in how family history is collected, and therefore used (or not) in a person's healthcare. Orientating an enquiry away from 'anything' and asking more specific details about particular conditions may help facilitate the dialogue.

\section{INTRODUCTION}

Family health history has been described as the first genetic test. ${ }^{1}$ A family health history is defined as a record of health information about a person and his or her close relatives.
Strengths and limitations of this study

- The patient cohort was Euro-centric, and not fully reflective of the ethnic population of New Zealand (where the study was carried out).

- The extent to which the family health history information had been previously shared/documented was not ascertainable.

- The study draws on range of routinely collected consultation studies with different purposes, and hence cover a wide range of general practitioner contexts, without specifically having a focus on family history.

A complete record includes information from three generations of relatives, including children, brothers and sisters, parents, aunts and uncles, nieces and nephews, grandparents, and cousins.' (National Institutes of Health, Genetics Home Reference). Such a detailed family health history is regarded as one of the most useful tools for risk assessment for common chronic diseases. ${ }^{2}$ It is estimated that the relative risks and ORs for various cancers, stroke, type 2 diabetes and cardiovascular diseases is twice that for people with an affected first degree relative, and more than four times greater for many of these diseases if there is more than one affected first-degree relative. ${ }^{2}{ }^{3}$ The value of health records from relatives has been recently demonstrated in research aimed at providing accurate predictions of disease risk: Truong et al showed that including health information from firstdegree relatives of those with both genomic and health records, had similar accuracies in polygenic risk scores with 44-fold larger population samples consisting of only genomic data and health information. ${ }^{4}$ Several professional organisations have recently made recommendations that general practitioners (GPs) routinely, and opportunistically, collect family health history for three generations. ${ }^{25}$ 
However, current evidence would indicate that there may be barriers to achieving this level of information, and approach to its collection, as family health history is widely reported as being both poorly and infrequently collected. ${ }^{67}$ Reported barriers to the collection of family health information include: poor reimbursement, provider's lack of time and expertise, lack of guidelines and adequate tools and limited functionality of electronic health information systems to capture and interpret data and unreliability of information provided by patients. ${ }^{89}$ The potential to improve healthcare by being able to act on family health history information is thus not being fully realised. This is important as access to genetic and genomic testing becomes easier and cheaper, available direct to the public and knowledge of family health history is imperative in wisely using this testing and interpretation of results. ${ }^{1} 1011$

The exploration of the practice of collection of family health history has tended to focus on the practical side, that is, to garner better understandings around the barriers and facilitators to its collection, and the validation and implementation of tools to collect family health history. ${ }^{21112}$ How family health history is actually discussed in routine primary healthcare consultations has received less attention, and to our knowledge this is first study to observe conversations about family health history in routine primary care consultations. The aim of our study was to explore language and patterns of communication relating to family health history observed in interactions between GPs and their patients within routine primary care consultations.

\section{MATERIALS AND METHODS}

Data source

Consultation data were sourced from the Applied Research on Communication in Health (ARCH) Corpus at the University of Otago, Wellington, New Zealand, ${ }^{13}$ and have been previously described. ${ }^{14}$ The Corpus houses a digitally stored collection of patient/practitioner consultation data that includes 458 videorecorded consultations, verbatim transcripts and selected medical notes. $^{15}$

\section{Identification of family health history consultations}

The consultations analysed in this paper were derived from five different studies that comprise the ARCH Corpus; in none of these was family health history the focus (table 1). At the time of this study, the Corpus included 252 patient-GP consultations involving 36 GPs, collected between 2004 and 2018. The ARCH Corpus includes a Microsoft Access database populated with metadata including full demographic information about every participant, research site information and free-text content logs of each consultation. The logs were prepared by a research nurse according to a standard template and include information about the main topics discussed, outcomes of the consultation (including prescriptions and referrals) and a minute by minute summary of key events and content. The logs thus capture any complaint or topic mentioned incidentally in a consultation, in addition to the main presenting complaint(s). The database and logs link electronically to full verbatim transcripts (including time measurements in minutes) and the original audio and videorecordings to facilitate subsequent more detailed analysis, but the latter cannot be queried directly via the database. ${ }^{15}$

A query was run on the Microsoft Access database of the logs of each GP consultation in the Corpus using the keyword 'family health history' (table 1 ). The term 'family health history' was present in the logs of 71/252 individual patient consultations with GPs. Further review of the transcripts was undertaken and the consultations were excluded if family health history was not discussed.

Table 1 Overview of the study and number of patient-GP consultations where family health history was discussed

\begin{tabular}{|c|c|c|c|}
\hline Study & Brief description of the original study & $\begin{array}{l}\text { No of } \\
\text { consultations } \\
\text { included in the } \\
\text { analysis }\end{array}$ & $\begin{array}{l}\text { No of } \\
\text { patient-GP } \\
\text { consultations in } \\
\text { original study }\end{array}$ \\
\hline Diabetes Study & $\begin{array}{l}\text { Tracking the contact of newly diagnosed patients with type } 2 \\
\text { diabetes with healthcare professionals over a } 6 \text { month period }\end{array}$ & 7 & 34 \\
\hline Interaction Study & Exploring clinical decision-making when rationing is explicit & 11 & 58 \\
\hline
\end{tabular}

\begin{tabular}{llcc}
$\begin{array}{l}\text { Talking About } \\
\text { Overweight and } \\
\text { Obesity }\end{array}$ & $\begin{array}{l}\text { When and how GPs and patients discuss excess weight related } \\
\text { issues (or not) during routine consultations }\end{array}$ & 6 \\
$\begin{array}{l}\text { Interpreting Study } \\
\text { Total }\end{array}$ & $\begin{array}{l}\text { Clinical risk and patterns of use and communication with/of } \\
\text { interpreters }\end{array}$ & 3 & 19 \\
\hline
\end{tabular}

GP, general practitioner. 
Additional terms were also included at this time to identify if family health history was mentioned in another context and included 'family history'; 'family'; 'whānau' (family); 'inherited'; and 'condition'. It is possible that not all relevant consultations in the Corpus were identified; however, the purpose was to collate a relevant dataset adequate for the purpose of undertaking a descriptive qualitative analysis, and not to investigate the frequency of occurrence of family health history.

\section{Patient and public involvement}

Patients were not involved in any aspects of the study design, including plans for dissemination of the research findings. As part of the original consenting process, they would have been advised on the length of the time required to participate in the research.

\section{Data analysis}

Themes were derived iteratively using a qualitative inductive approach based on the verbatim transcripts of interactions between patients and GPs. ${ }^{16}$ Our overarching aim was to report on the emerging range of issues and communication styles without pre-conceived assumptions. SF (health services researcher) read all of the transcripts $(\mathrm{n}=71)$ several times and identified the conversation sequences that related to family health history, including the time in the consultation that it was first mentioned. A subsample of transcripts were read by RJ (GP and health services researcher). Twelve initial inductive themes were derived (table 2) that formed the coding frame, the transcripts were then reread and new codes emerged as preliminary themes. These themes were mapped across all of the transcripts, reread and recoded until no further themes emerged and the final themes derived (table 2). Where additional clarity or interpretive information was required, the videorecording of the consultation was reviewed. Initial interpretations of the themes were shared with the team and discussed in detail discussion between SF and RJ. MHS,
Table 3 Self-reported ethnicity of patients who participated in the original studies

\begin{tabular}{ll}
\hline Self-reported ethnicity & Frequency \\
\hline New Zealand European & 41 \\
\hline New Zealand European/Māori & 2 \\
\hline New Zealand European/Cook Island Māori & 2 \\
\hline Māori/ Samoan/UK/US & 2 \\
\hline New Zealand European/Samoan & 2 \\
\hline Samoan & 8 \\
\hline Tongan & 2 \\
\hline Assyrian & 1 \\
\hline Chinese & 2 \\
\hline Dutch & 2 \\
\hline Dutch/New Zealand European & 1 \\
\hline Indian & 2 \\
\hline Italian & 1 \\
\hline Somali & 1 \\
\hline Sri Lankan & 1 \\
\hline Thai & 1 \\
\hline Total & 71 \\
\hline
\end{tabular}

a researcher with experience in interactional sociolinguistics contributed to an additional round of discussion and interpretation. The themes were discussed and agreed by consensus with all of the authors. The sociodemographic information of the 71 patients was reviewed after the first round of analysis and self-identified ethnicity reported in table 3 analysis by ethnicity was not undertaken.

\section{RESULTS}

Fifty-eight out of a possible 252 (23\%) patient-GP consultations involved at least one mention of family health

Table 2 Thematic structure

\begin{tabular}{lll}
\hline Inductive codes & Preliminary themes & Final themes \\
\hline Blindsiding & Open question & Non-specific line of enquiry \\
GP closed question & Closed question & Specific line of enquiry \\
GP contextualising & Health condition &
\end{tabular}

GP health promotion

Knowing the GP

Not knowing

Not getting very far

Patient position

Isolation

Health condition Why asked

Lifestyle advice

$\begin{array}{lll}\text { How asked } & \text { GP multitasking } & \text { Multitasking } \\ \text { GP position } & \text { Patient multitask response }\end{array}$

GP, general practitioner. 
history. Since most patients came to the consultation with more than one reason for their visit, the resultant interaction between the GP and the patient was a dynamic exchange of information, often covering several points of discussion. The length of each individual consultation ranged from 6 to $37 \mathrm{~min}$ duration. Sharing or updating family health history was never the presenting reason for the consultation. In the 58 consultations, 46 conversations about family health history were initiated by the GP. Most discussions around family history lasted for between 1 and $2 \mathrm{~min}$. Two overarching themes were developed from the transcripts that described how family history was raised, and then subsequently discussed, in the consultation-non-specific and specific enquiry; and one theme which related to the situational context, multitasking (table 2).

\section{How family health history is raised in the consultation}

The topic of family health history was presented initially to the patient in one of two ways, through a line of nonspecific enquiry or through a specific context (table 4). Patients often responded to either approach with a simple 'no', but fuller negative responses also occurred regularly and typically included an account of some kind-for example, that the patient was unable to be certain or to provide the requested information (eg, explaining family relationships/dynamics which impeded or prevented their access to information).

\section{Non-specific enquiry}

A non-specific line of enquiry was initiated through prompt questions that were tilted towards a 'no' answer, typically asking the patient if there was 'anything that runs in the family' or if there was 'anything in the family we should know about?'.

The introduction of the topic through this form of non-specific enquiry, while sufficient to initially engage the patient, elicited two opposite types of responses, one where the patient disclosed very little or one where the patient disclosed a significant amount of information.

Where patients responded by not disclosing any information, this often ended any further discussion about family history, with no further details being drawn out by the GP. Following this, the direction of the consultation tended to change abruptly into a different topic, as illustrated by the following interaction:

GP: ... and anything that runs in your family at all on either your mum or dad's side?

PT: No not that I know of

GP: Nope

GP: Fine, and have you ever had a smear test?

(ARCH:TS GP08-17)

Those patients who responded positively to the initial response to the prompt to share 'anything' or discuss 'any' history did so by presenting a picture of family health that had personal meaning to them, and at the same time oriented to the doctor's agenda by highlighting aspects that were clinically relevant. For example:
GP: I've got your details and medication, any history of

PT: Parents are in the seventies and still alive

GP: Good

PT: Apparently my grandmother ended her life in the gas oven at home so I guess she would have lived a long life if she hadn't of done that

GP: $\mathrm{Mm}$

PT: Grandfather on the other side was an alcoholic so that sort of explains why he's dead

GP: Right

PT: The other set of parents are fine

GP: And the other grandparents

PT: Oh grandparents? One died on the operating table and um, he was sixty odd, and my grandmother would have been in her seventies as well I think'

At this point of the consultation, the GP changed to a more specific line of enquiry (inferably following a checklist) by asking about the occurrence of specific health conditions, and it followed as:

GP: Anyone had diabetes in the family?

PT: No

GP: And high blood pressure?

PT: No

GP: Um alcoholism it was your mother's father or your father's father?

PT: Oh my mother's father grandfather, but it's all largely hearsay

GP: Yep

GP: Any significant mental illness?

PT: No, we seem to be pretty straight up

GP: And familial degenerative disease, which I don't actually understand what that means, so we'll leave that blank

PT: Once again they're all seventy they're not in the mental asylums and they're living in their own homes without nursing and wheelchairs so that's pretty good

(ARCH:IS-GP02-08)

In this interaction initially it appeared that the patient wasn't going to share family health history information by stating 'Parents are in the seventies and still alive', which suggests that they felt this was sufficient in describing a picture of family health. However, they went on to share more details, despite being prompted initially by a nonspecific line of enquiry, with the patient disclosing that alcohol misuse and mental health conditions did exist in their family. Of note is that while this patient disclosed that a relative died by suicide, and that there was alcohol misuse, they did not appear to attribute this to poor mental health, instead discounting the reliability of the information passed down, by saying it was 'hearsay'. After several specific questions about the occurrence of particular health conditions, the GP ended the enquiry by saying And familial degenerative disease, which I don't actually understand what that means, so we'll leave that blank' to which the patient augmented their initial response by stating 'Once again they're all seventy they're not in the mental asylums and they're living in their own homes without nursing and wheelchairs so that's pretty 


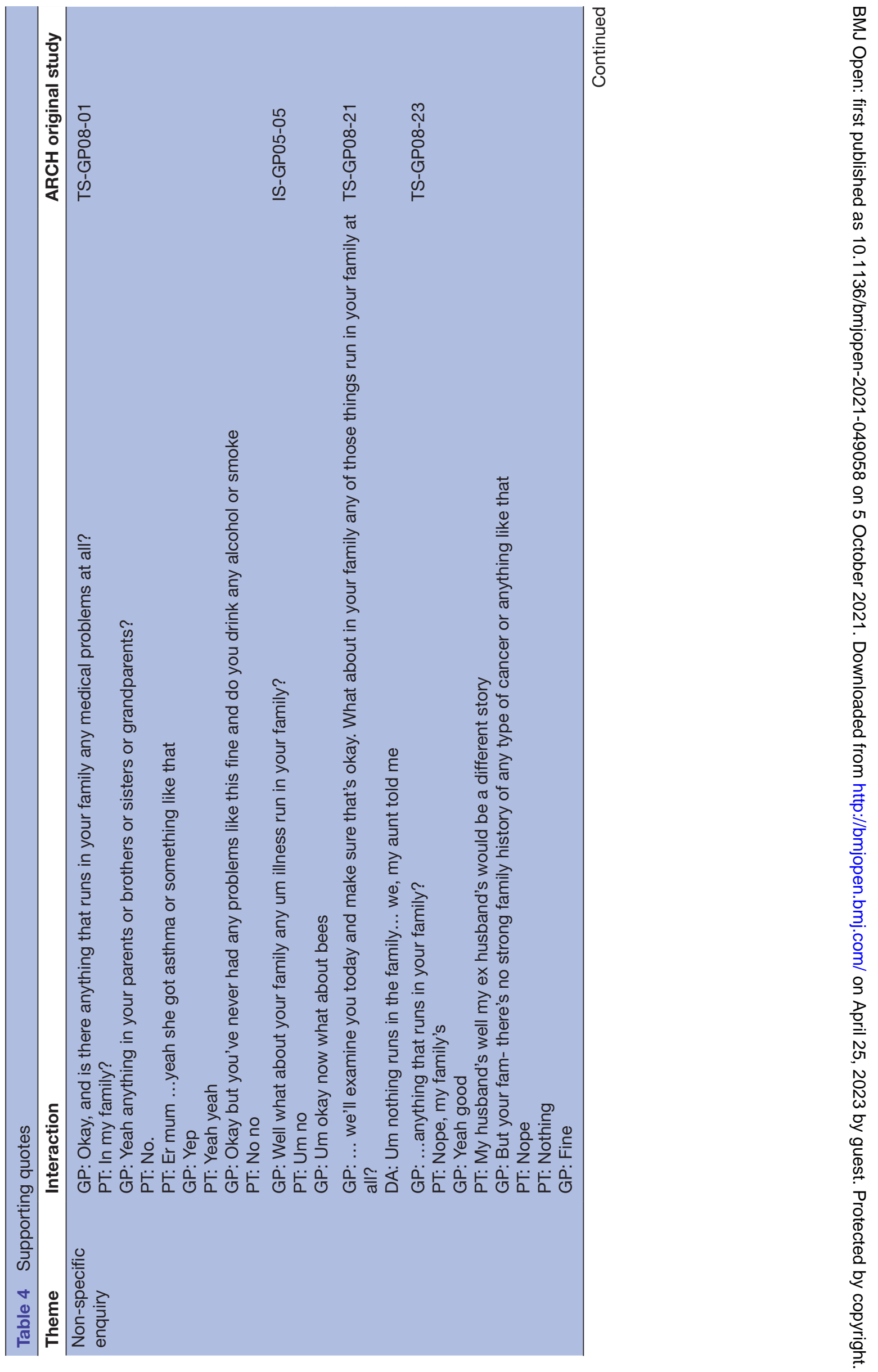



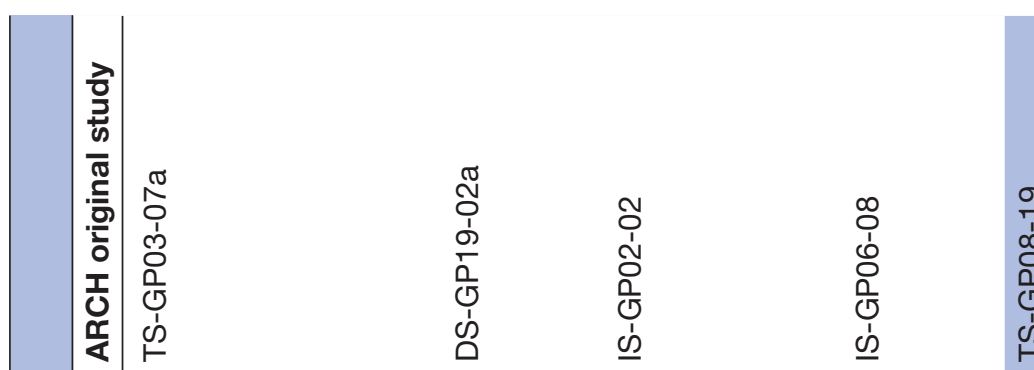

$\underline{\omega}$

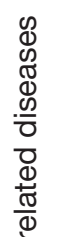

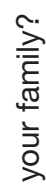

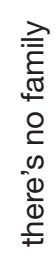

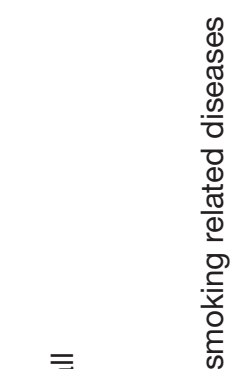

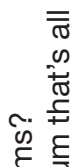<smiles>[CH]=CCCCCC</smiles>

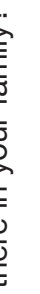

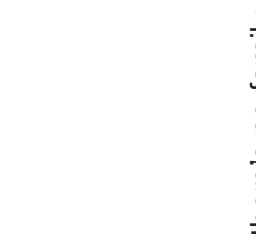

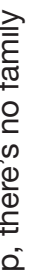

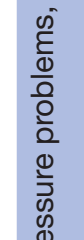

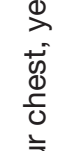

竞

है

응 공.

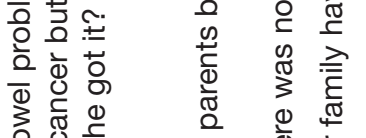

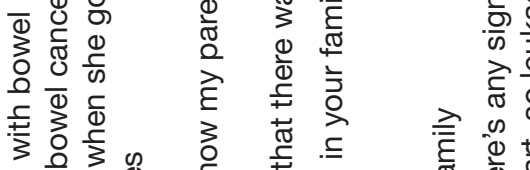

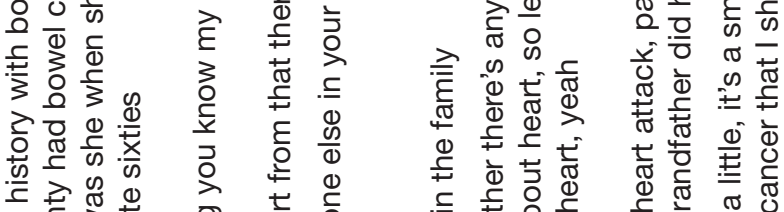

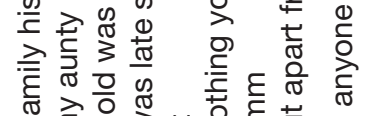

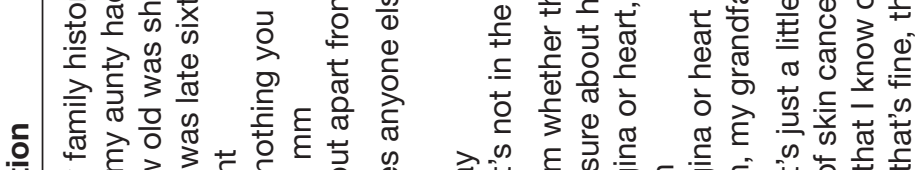

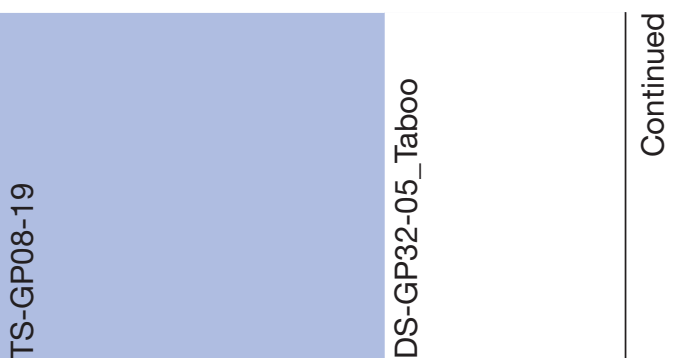

ن

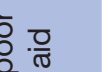

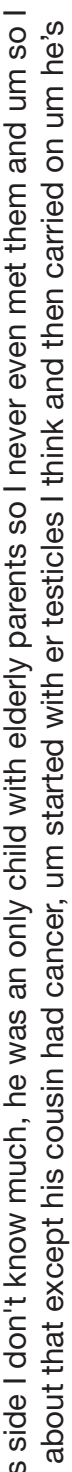

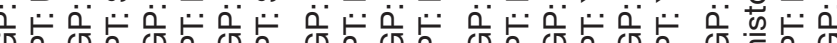

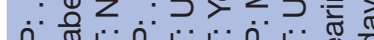

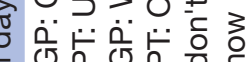
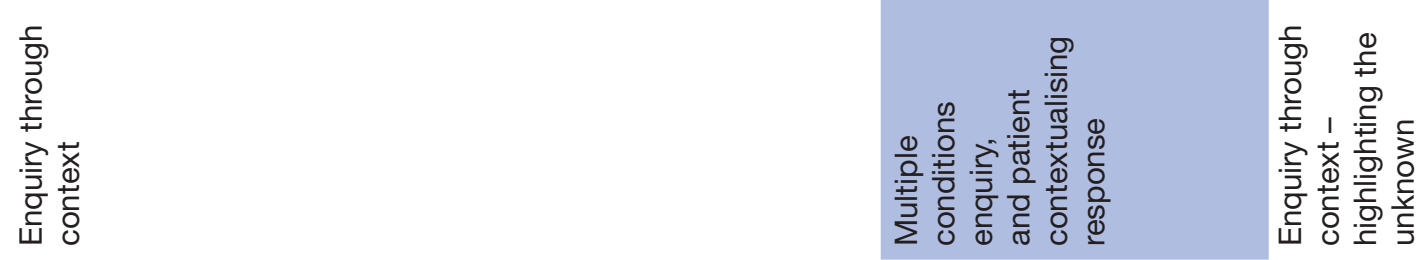


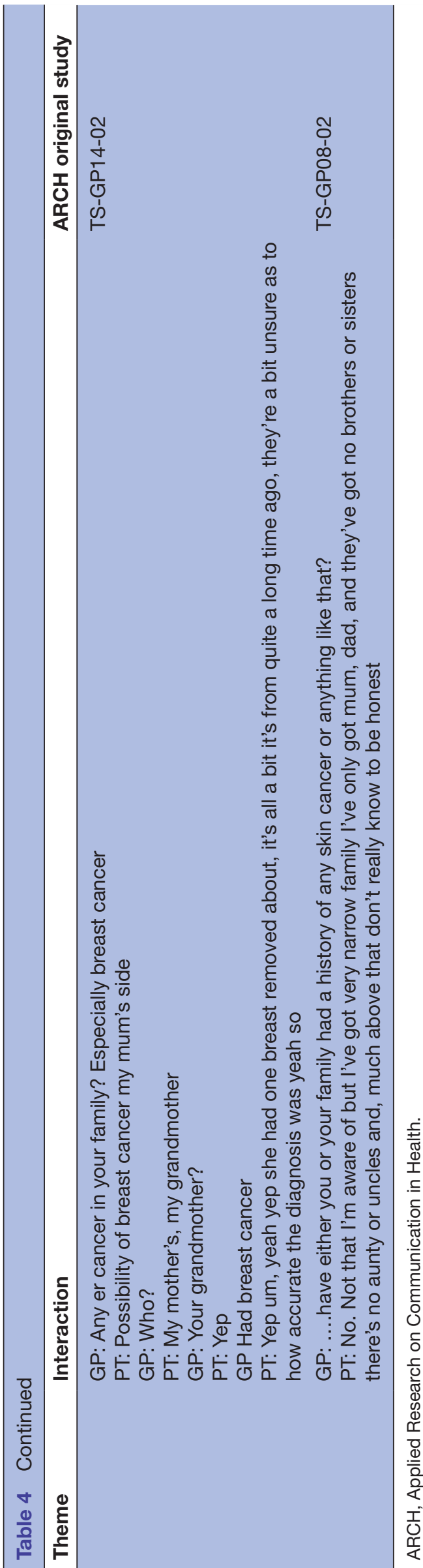

good, at which point the discussion changed topic. A more extended dialogue about family health was not established.

\section{A more specific enquiry through context: highlighting the unknown}

In comparison, more specific lines of enquiry were evident when the GP was wanting to establish the occurrence of a particular condition, which in this cohort was mainly about the occurrence of heart disease, diabetes, cancers and/or the existence of allergic reactions to particular medications (table 4 ). This line of enquiry was frequently premised by asking the patient if there was a 'strong family history' of a particular condition; although the adjective 'strong' was never defined nor questioned by any of the patients. With a more specific enquiry, the patient was often asked to think about more than one condition (table 4), for example when this patient was seeking a repeat prescription for hormonal contraceptive:

GP: You or your family have never had any sort of blood clot or thrombosis or a stroke or blood pressure is there a strong family history of breast cancer at all?

PT: No, not that I know of

GP: No, fine, fine.

PT: I live with my father so I don't really know much about my mother's side of the family

GP: Yeah okay. And have you had any medical problems in the past?

PT: No.

\section{(ARCH:TS-GP08-07)}

Exploring this interaction further, the use of the words 'never' or 'any' in the first three-part question orientated the response to a negative, and the doctor left no space for a response, continuing straight on to the next question, suggesting this was a request for confirmation rather than a question seeking specific information. In all cases, as we see in the response to the doctor's second question here, a more specific line of enquiry placed an onus of recall on the patient, as with a non-specific line of enquiry, but had the additional effect of orientating the patient to wanting to be as accurate as possible. In this example, we see the patient added "not that I know of' and an explanation as to why they do not know all or some of the answer (at that given time). Estranged family relationships were frequently reported to account for why patients did know about the occurrence of specific health conditions. As exemplified by another patient disclosing:

GP: Yep so um well-apart from that is there anything that runs in your family that might trigger it thyroid problems or auto-immune problems or nothing else?

PT: Nothing that I know of um I mean I don't know my father that well but um, I've kind of asked him a few questions but he's had nothing he's only just got heart disease and stuff like that

GP: Okay.

\section{(ARCH:TS-GP10-16)}

Where patients indicated that they did not know (much) about their family health history, there was no 
indication that they would have been able to ascertain a more detailed family history if they knew they were going to be asked about it, nor did any patient say in the consultation that they would attempt to find out more. Once an estranged family had been raised by the patient, the GPs made no more enquiries to establish familial inheritance/occurrence, and the consultation was refocused to the individuals' health history.

\section{Multi-tasking}

In reviewing the video recordings, the GP could often be observed multitasking during the consultation (eg, looking at or adding to the electronic medical record, undertaking a physical examination), including at the time while asking the patient about their family health history. The patient was also expected to multitask, from having to think about answering more than one line of enquiry, and having to undertake tasks at the same time. The following excerpt exemplifies such an interaction:

GP: I will need your height and weight please as well, and do you have a family history of heart attacks or strokes? Without shoes please

PT: Um my mum she had a minor heart attack but she died um it'll be three years this year

GP: $\mathrm{Mm} \mathrm{hm}$

PT: Um from cancer

GP: Mm what kind of cancer?

PT: Um they're not really sure

GP: Stand here please

PT: Cos they don't know where it started

GP: Yeah

GP: Sometimes has that, okay, that's perfect

PT: Oh okay, what height am I?

GP: One fifty six

(ARCH:DS-DP32-08)

This consultation commenced with a 'so' to which the patient explained the reason for their visit. Within $1 \mathrm{~min}$ the GP had turned their back to the patient, and started typing. Two minutes into the consultation, the GP started experiencing problems with the computer (data entry) and said to the patient 'ahhh don't you hate computers?'. The patient in this instance did not appear relaxed, they were wringing their hands and swinging their legs under the chair. The topic of family history was raised approximately $5 \mathrm{~min}$ into the $13 \mathrm{~min}$ consultation, where the patient was given a statement of intent-that their height and weight would need to be taken, asked a question-about their family history, and an instruction-to remove their shoes. In response to the doctor's question about family history of heart attack or stroke, the patient disclosed that her mother had died 3 years ago. At this point the GP was not making eye contact with the patient, and during the explanation of what her mother had died from the patient was given another instruction to go and stand in a particular place. While family health history information was able to be shared, because it was done in a context of multitasking, it appeared to create a perfunctory transaction, rather than a discussion.

\section{DISCUSSION}

This paper reviewed how family history was discussed in a sample of archived primary healthcare consultations. To our knowledge, this study is the first to observe conversations about family health history in routine primary care consultations. The majority $(46 / 58)$ of conversations about family health history were initiated by the GP. Most of these family history discussions lasted approximately 1-2 min. Patients were invited to share family health history through one of two ways; non-specific enquiry such as asking 'anything that runs in the family?', or in relation to a specific condition where patients were asked if they had a 'strong family history' of a particular condition, like breast cancer. The majority of patients responded to either approach by replying 'no' or premising the negative reply by explaining family relationships or dynamics which would impede or prevent access to such information. Of note is constraints of primary care consultations on family health history taking. 'Multitasking', and computer use also appeared to have an influence on how family history taking played out. These aspects have been noted in other areas of primary care performance and, once understood, strategies can be put in place to mitigate their impact. ${ }^{17}$

Sharing of family history information with family members and health-professionals is influenced by the sociocultural norms of the family it pertains to and the purpose for which the information is being sought. ${ }^{18-21}$ There are multiple meanings of 'family' and varying beliefs about what 'health' (and illness) means. ${ }^{19} 20$ Furthermore there are different reasons for collecting family health history information, for example, to establish genetic risk to identify which patients need referral for specialist genetics assessments ${ }^{21}$; to establish the prevalence of complex chronic diseases ${ }^{3}$; or to establish family systems genogram ${ }^{21}$ or potentially for all of the aforementioned reasons. However, if this is not established prior to the enquiry being made, the healthcare interaction may result in misaligned communication because there has been an assumed shared understanding of what is meant by 'family health history'. ${ }^{20} 22$ This was frequently observed in our study. While no patient questioned why family health history was being enquired about, there was no indication given by the GPs as to why it was being asked about. It is not possible to ascertain whether indicating the purpose of the enquiry would have resulted in more aligned discussions and this warrants further investigation.

As part of realising the use of family health history more routinely, there is an emerging expectation that people will collect their family health information through the use of online family health history tools. ${ }^{212}{ }^{23}$ In 2010 , the US Surgeon General suggested that Thanksgiving Day be also called 'Family Health Day' because families often get together, providing an opportunity to discuss and collect family health history from several family members. ${ }^{24}$ In parallel the US Surgeon General released a free online tool for the collection of family health 
history. ${ }^{25}$ The use of family health history tools has been shown to improve the detection of inherited conditions and cancer in research studies. ${ }^{2}$ However, there are considerations for the use of such tools in routine practice. As with other family health history tools, this tool reflects a narrow biomedical definition of the family ${ }^{20}$ which raises questions about the relevance and potential acceptability of such tools for many families, including for those observed in our study. Multiple approaches that incorporate both social and biological/medical elements are likely to result in more equitable access to and greater benefit from family history information in healthcare.

In our study, enquiring about family health history lasted between 1 and $2 \mathrm{~min}$. A 'full' family history includes three generations of relatives, health problems with age of onset for each family member, and age of each relative at death with cause has been estimated to take up to $30 \mathrm{~min} .{ }^{26}$ Dedicated consultations for the collection and documentation of family health history have been proposed as potential solutions to these system level constraints. ${ }^{2}$ However, this approach could potentially create inequities in access to (and therefore benefit from) family history collection for those people who are unable to pay for and/or attend additional consultations.

In previous studies, GPs have reported that the information that patients do provide about their family history is unreliable. ${ }^{8728}$ Our study demonstrates that the way GPs enquire about family health history may also contribute to the amount and type of information that is gathered. Another study exploring how GPs could meet patients unmet needs in acute care consultation found that changing the orientation of the enquiry by using the question 'Is there something else you want to address in the visit today?' led to significantly more unmet needs being eliminated than when GPs used the question 'Is there anything else you want to address in the visit today? ${ }^{29}$ Although the paper reports an randomised controlled trial that was conducted in the context of eliciting additional concerns, but its relevance extends beyond this topic - the key point is that choosing 'anything' rather than 'something' in asking the question signals that that the expected answer is 'no'. Hence this finding is relevant to history taking as well as problem presentation. It would be worth exploring if such attention to linguistics would help improve the collection of family health history. In a further study, when patients were asked to consider family health history, the addition of 'extended' to family health history yielded patients reporting positive family history for 8 of 11 medical conditions. ${ }^{26}$ In our data, the abrupt shift in consultation topic after a negative initial response to family history is indicative of many interactions in primary care where there are competing demands in a checklist driven consulting environment. ${ }^{30}$ With increasing expectations that family health history is collected, such communication devices may help to enhance interactions and obtain more relevant information
A limitation of this study is that the patient cohort was Euro-centric, and not fully reflective of the ethnic diversity of New Zealand (where the study was carried out). We have not undertaken any analysis by ethnicity, and this is warranted in future research. It was also not possible to ascertain the extent to which the family health history information that was shared was taken into account in any clinical decision making by the GP. Nor was it possible to ascertain whether other healthcare practitioners had had prior discussions with patients about their family history, or if this information had been collected and recorded elsewhere in the patient records. A strength of this study is that these examples are taken from a range of routinely collected consultation studies with different purposes, without a specific focus on family history, and hence cover a wide range of GP contexts.

This study has highlighted areas where inequities may arise with existing methods of routine collection of family health history. The opportunistic enquiry into family health history is more complex than asking if 'anything runs in the family' and, with attention to linguistic devices and acknowledgement of patient social and cultural norms, there is an opportunity to expand history taking to the point at which the history can become an effective genomic tool.

\section{Author affiliations}

${ }^{1}$ Department of Obstetrics, Gynaecology and Women's Health, University of Otago, Wellington, New Zealand

${ }^{2}$ Department of Primary Health Care and General Practice, University of Otago, Wellington, New Zealand

${ }^{3}$ Department of Medicine, University of Otago, Wellington, New Zealand ${ }^{4}$ Te Rōpū Rangahau Hauora a Eru Pōmare, Department of Public Health, University of Otago, Wellington, New Zealand

${ }^{5}$ Te Tumu, School of Māori, Pacific and Indigenous Studies, University of Otago, Dunedin, New Zealand

${ }^{6}$ Department of Mathematics and Statistics, University of Otago, Dunedin, New Zealand

Twitter Maria H Stubbe @chttr and Rebecca Grainger @drbeckyg

Acknowledgements The authors thank Jo Hilder and Rachel Tester for helping to develop the search strategy and data retrieval, and the GPs and patients who generously contributed their data to the ARCH Corpus of Health interactions. This research was funded by the University of Otago, Aotearoa New Zealand.

Contributors SF conceived the idea, led the analysis and drafted all versions of the manuscript. MHS contributed to the study design, analysis and manuscript preparation. RG contributed to the study design, analysis and manuscript preparation. BR contributed to the study design, analysis and manuscript preparation. KP contributed to the study design, analysis and manuscript preparation. PW contributed to the study design, analysis and manuscript preparation. RJ contributed to the study design, analysis and manuscript preparation. AD contributed to the study design, analysis and manuscript preparation.

Funding This work was supported by The University of Otago Research Grant. Award/Grant number is not applicable.

Competing interests None declared.

Patient and public involvement Patients and/or the public were not involved in the design, or conduct, or reporting, or dissemination plans of this research.

Patient consent for publication Not required.

Ethics approval The collection of all Corpus data and guidelines for subsequent use have been approved by the New Zealand Health and Disability Ethics Committee and University of Otago Human Ethics Committee (Health). Ethics 
approval for this study was given by the University of Otago Human Ethics Committee (Health) (H19/022).

Provenance and peer review Not commissioned; externally peer reviewed. Data availability statement № additional data available.

Open access This is an open access article distributed in accordance with the Creative Commons Attribution Non Commercial (CC BY-NC 4.0) license, which permits others to distribute, remix, adapt, build upon this work non-commercially, and license their derivative works on different terms, provided the original work is properly cited, appropriate credit is given, any changes made indicated, and the use is non-commercial. See: http://creativecommons.org/licenses/by-nc/4.0/.

\section{ORCID iDs}

Sara Filoche http://orcid.org/0000-0002-0874-6494

Rebecca Grainger http://orcid.org/0000-0001-9201-8678

\section{REFERENCES}

1 Bennett RL. Family health history: the first genetic test in precision medicine. Med Clin North Am 2019;103:957-66.

2 Ginsburg GS, Wu RR, Orlando LA. Family health history: underused for actionable risk assessment. Lancet 2019;394:596-603.

3 Wattendorf DJ, Hadley DW. Family history: the three-generation pedigree. Am Fam Physician 2005;72:441-8.

4 Truong B, Zhou X, Shin J, et al. Efficient polygenic risk scores for Biobank scale data by exploiting phenotypes from inferred relatives. Nat Commun 2020;11:3074.

5 Royal Australian College of General Practitioners. Genomics in general practice. East Melbourne, Victoria: Royal Australian College of General Practitioners, 2019.

6 Haga SB, Orlando LA. The enduring importance of family health history in the era of genomic medicine and risk assessment. Per Med 2020;17:229-39.

7 Murff HJ, Greevy RA, Syngal S. The comprehensiveness of family cancer history assessments in primary care. Community Genet 2007;10:174-80.

8 Daelemans S, Vandevoorde J, Vansintejan J, et al. The use of family history in primary health care: a qualitative study. Adv Prev Med 2013;2013:1-8.

9 Cleophat JE, Nabi H, Pelletier S, et al. What characterizes cancer family history collection tools? A critical literature review. Current Oncology 2018;25:335-50.

10 Guttmacher AE, Collins FS, Carmona RH. The family history--more important than ever. N Engl J Med 2004;351:2333-6.

11 Khoury MJ, Feero WG, Valdez R. Family history and personal genomics as tools for improving health in an era of evidence-based medicine. Am J Prev Med 2010;39:184-8.

12 Welch BM, Dere W, Schiffman JD. Family health history: the case for better tools. JAMA 2015;313:1711-2.

13 Applied Research on Communication (ARCH) Group. Applied research on communication in health, 2020. Available: http://www. otago.ac.nz/wellington/research/arch/
14 Stubbe M. Evolution by Design: Building a New Zealand Corpus of Health Interactions. In: Marra MW P, ed. Linguist at work. Wellington: Victoria University Press, 2017: 196-214.

15 Univeristy of Otago Wellington. Arch corpus of health interactions. Available: https://www.otago.ac.nz/wellington/research/arch/corpus/ index.html\#statistics2020

16 Braun V, Clarke V. What can "thematic analysis" offer health and wellbeing researchers? Int J Qual Stud Health Well-being 2014;9:26152.

17 Dowell A, Stubbe M, Scott-Dowell K, et al. Talking with the alien: interaction with computers in the GP consultation. Aust J Prim Health 2013;19:275-82.

18 Campbell-Salome G, Rauscher EA, Freytag J. Patterns of communicating about family health history: exploring differences in family types, age, and sex. Health Educ Behav 2019;46:809-17.

19 Canary HE, Elrick A, Pokharel M, et al. Family health history tools as communication resources: perspectives from Caucasian, Hispanic, and Pacific Islander families. J Fam Commun 2019;19:126-43.

20 McGrath BB, Edwards KL. When family means more (or less) than genetics: the intersection of culture, family and genomics. $J$ Transcult Nurs 2009;20:270-7.

21 Wilson BJ, Carroll JC, Allanson J, et al. Family history tools in primary care: does one size fit all? Public Health Genomics 2012;15:181-8

22 Hunt K, Emslie C, Watt G. Lay constructions of a family history of heart disease: potential for misunderstandings in the clinical encounter? Lancet 2001;357:1168-71.

23 Cleophat JE, Nabi H, Pelletier S, et al. What characterizes cancer family history collection tools? A critical literature review. Curr Oncol 2018;25:335-50.

24 National Human Genome Research Institute. This Thanksgiving celebrate national family health history day, 2010. Available: https:// www.genome.gov/27559631/this-thanksgiving-celebrate-nationalfamily-health-history-day/

25 Facio FM, Feero WG, Linn A, et al. Validation of my family health portrait for six common heritable conditions. Genet Med 2010;12:370-5

26 Conway-Pearson LS, Christensen KD, Savage SK, et al. Family health history reporting is sensitive to small changes in wording. Genet Med 2016;18:1308-11.

27 Mathers J, Greenfield S, Metcalfe A, et al. Family history in primary care: understanding GPs' resistance to clinical genetics--qualitative study. Br J Gen Pract 2010;60:e221-30.

28 Williams JL, Collingridge DS, Williams MS. Primary care physicians' experience with family history: an exploratory qualitative study. Genet Med 2011;13:21-5

29 Heritage J, Robinson JD, Elliott MN, et al. Reducing patients' unmet concerns in primary care: the difference one word can make. J Gen Intern Med 2007;22:1429-33.

30 Dowell A, Stubbe M, Macdonald L, et al. A longitudinal study of interactions between health professionals and people with newly diagnosed diabetes. Ann Fam Med 2018;16:37-44. 